\title{
A configurable architecture for e-participatory budgeting support
}

\author{
Cesar Alfaro, Javier Gomez*, Jose M. Lavin**, Juan J. Molero*** \\ Dept. of Statistics and Operations Research, Universidad Rey Juan Carlos, cesar.alfaro@urjc.es, “javier.gomez@urjc.es, \\ **josemaria.lavin@urjc.es, ***juanjose.molero@urjc.es
}

\begin{abstract}
Participatory budgets are emerging as a paradigm for participation. However, there are many variants of such experiences suggesting a look of general methodology. Moreover there is a little use of ICT in this application context. We present a configurable architecture for e-participatory budget formation support.
\end{abstract}

Keywords: participatory budgeting, e-participation, technology support, ICT

Acknowledgement: Research supported by grants from Spanish Ministry Science and Innovation, and E-Democracia CM

S

ince the 1960's, an increasing apathy and feeling of alienation among citizens has led to the so-called democratic deficit (Sttefek et Al, 2008), which has entailed an increasing interest in promoting participatory processes, which allow citizens to take part in public policy decision making. Participatory processes are on a clear rise for reasons including: increase of legitimacy, acceptance and transparency in decisions made; approaching decisions to citizens; taking advantage of the local knowledge that citizens might have; educate politicians, remembering them that they are elected to represent citizens and mitigate patronage; educate citizens to make them understand that decisions entail both benefits and costs that need to be somehow balanced; enhance diversity, including additional perspectives on a problem; and, reduce the apathy which causes the above mentioned democratic deficit.

A reference example is that of participatory budgets (PBs), which allow citizens to take part in making decisions on how part of a public budget is spent. There are many variants of PBs, as described in Alfaro et Al (2010) three of which (Salford, Porto Alegre and Getafe) will be shown here. Another important issue is that little technology has been used in all experiences that we have analyzed. This leads us to describe a generic configurable architecture for e-Participatory budgeting support.

\section{Participatory Budgets}

Participatory budgets (PBs) are emerging as a paradigm for participation, especially at local level; (Sintomer et Al, 2008). They constitute an attempt to allow citizens to have a word on the decision of how part of a public budget is spent, mainly in municipalities. It is a budget allocation approach based on dialogue and citizen participation, which diverges from the current predominant representative model. In a sense, PBs are transforming the idea of a representative democracy, in which the citizen's input is considered just at the moment of elections, to move closer to a participatory democracy, based on direct participation and debate.

Early experiences with participatory budgeting took place in Kerala, Lajes, Boa Esperança, Diadema and Vila Velha. However, the most well known, and longest lasting. PB experience comes from Porto Alegre, in Brazil (initiated in 1989, permanently adopted in 1992), acclaimed for 
both the efficient and democratic management of urban resources it has made possible. PBs are becoming increasingly popular in many other places, all around the world. Recent reports indicate that more than one hundred municipalities in Europe, covering more than four millions citizens are implementing these PB processes, (Sintomer et Al, 2008). The announcement of the UK government in year 2006 that all municipalities should implement PB experiences by 2012 is symptomatic in this respect, (Röcke, 2008). PBs have appeared not only in Europe or South America, but also in other countries including China, the Dominican Republic, India, Indonesia, Serbia or South Africa.

There are many variants of PBs. In some cases, they consist, only, of an informative event, so that citizens do not participate directly in decision making. In other cases, PBs entail an intensive participation procedure, using, for instance, voting or negotiation sessions. As an illustration, we briefly describe three experiences based on different participation mechanisms.

- In Salford, United Kingdom, the first PB experience was promoted by the Labor government with the support of Community Pride, (Sintomer, 2004). The process begins with consultation meetings in which all citizens are invited to present their proposals on issues such as the budget, the quality of public services, taxes,... Citizens may also send their proposals by post or online. When the meetings finish, the City Council has to decide how to spend the budget using a resource distribution matrix: it mediates, through weightings and indicators, between the needs expressed by citizens and the needs of an area. Thus, even if citizens do not participate directly in decision making, their views should influence the final result.

- In Porto Alegre, southern Brazil, in 1988 the new government tried different ways to provide more power to the citizens and change the priorities in public expenditure, approaching them to the less privileged classes. In this context, the first PB experiments took place in 1989, as a new way of elaborating the municipal budget. Participation in Porto Alegre is organized through seventeen regions, defined according to geographic, social and community criteria. Every year, all citizens are invited to participate at the PB process. In the beginning, citizens receive basic information about the city budget in meetings at district level and delegates elected from those attending these meetings draw up a list of priorities for projects in the forthcoming budget. The next step is to vote to assign priorities to projects, and elect two delegates from each district. The investment resources are distributed among regions and thematic categories using a two step procedure which generates a budget matrix. The available budget is distributed among thematic categories, and citizens vote, in regional assemblies, on thematic priorities. When this step is finished, the available budget is distributed among the thematic categories proportionally to the total points received. In a second step, the budget allocated to each specific thematic category is distributed among the seventeen regions according to a formula combining three criteria: the total population, the lack of services or infrastructures and the thematic priority that has been given by citizens in each region. At the end of the process, the Investment Plan is subject to approval by the Municipal Council.

- In Getafe, Spain, participatory budget processes have been gradually evolving since 2003. Opportunities for participation are broadly announced in different media: the council monthly newspaper, the council website, local press, radio, leaflets and posters. An important strategy is also the involvement of local intermediaries (schools, citizen associations, youth and sport centres, etc.) in the recruitment process, which are intended to activate under-represented citizen groups (youth, elderly, socially disadvantaged...). At the beginning, citizens can submit proposals by post, at locally held neighbourhood meetings or online. Proposals sent by post are, then, presented at meetings and on an Internet platform for further discussion. At the end of each meeting participants can express their preferences by voting. To do so, every participant must rank their favorite three proposals in order of preference, giving three points to their most preferred, two to their second preference, and one to their third one. When the voting finishes, the technical staff examines the five most voted proposals to determine its technical, economic and legal viability. Finally, list of proposals is forwarded to the borough assembly for final 
decision making. In this phase, citizens are invited to take part in the public debates of the technical committees.

\section{A general approach}

Through the analysis of various PB experiences, around the world, we have identified standard tasks which appear in various PB applications, possibly scheduled in different ways. These are:

- Problem Structuring. The problem is structured before a final list of proposals is identified. In this phase, technicians determine criteria for choosing between investment proposals, elaborate an initial list of projects in which to spend the budget, together with their associated costs, technical features and constraints among them. Sometimes problems might not be clearly formulated and participants would spend time structuring the problem, dividing them into parts so as to better apprehend it. In this phase, technicians determine criteria for choosing between investment proposals, elaborate an initial list of projects, together with their associated costs, technical features and constraints among them.

- Debating. Participants can express their opinions and discuss a list of projects. They also propose new projects and criteria, possibly supervised by a decision analyst, to consolidate a final list of proposals.

- Preference Modelling. Participants analyze the allocation problem individually and determine their personal preferences which are used to evaluate feasible budgets as well as obtain their preferred budget.

- Negotiation. Participants are allowed to make offers proposing in which projects to spend the budget and discuss them through a forum. Participants can accept or reject each proposed offer. Individuals are supported in the construction of offers and the evaluation of received offers using decision analytic tools. Several negotiation methods could be used, such as POSTING or balanced increment method (Rios \& Rios Insua, 2008).

- Voting. Participants could express their budget priorities or choose their representatives through voting sessions. To do so, several voting schemes could be used, such as approval voting, Borda Count, majority rule or cumulative voting.

- Arbitrating. Through debate and negotiation, we may find that the parties involved cannot be satisfied and refuse to budge from their positions. To avoid this, many mechanisms include the figure of an arbitrator who makes the final decision once the opinions and reasoning of the different parties have been presented.

- Sampling. A group of representative is sampled randomly to take part in the decision making process.

Within such processes, we shall also typically identify:

- The problem owner which is the entity which aims at solving a participatory budget problem.

- The participants, who provides input to the participatory budget decision process, mainly his opinions and preferences about which projects to include in the budget.

- The technical staff, who supports technically the process software development: Typically, they will work for the problem owner and interact and assist the participants. 
We present in Figure 1 how the above phases are combined and performed in the cases described in Section 1.

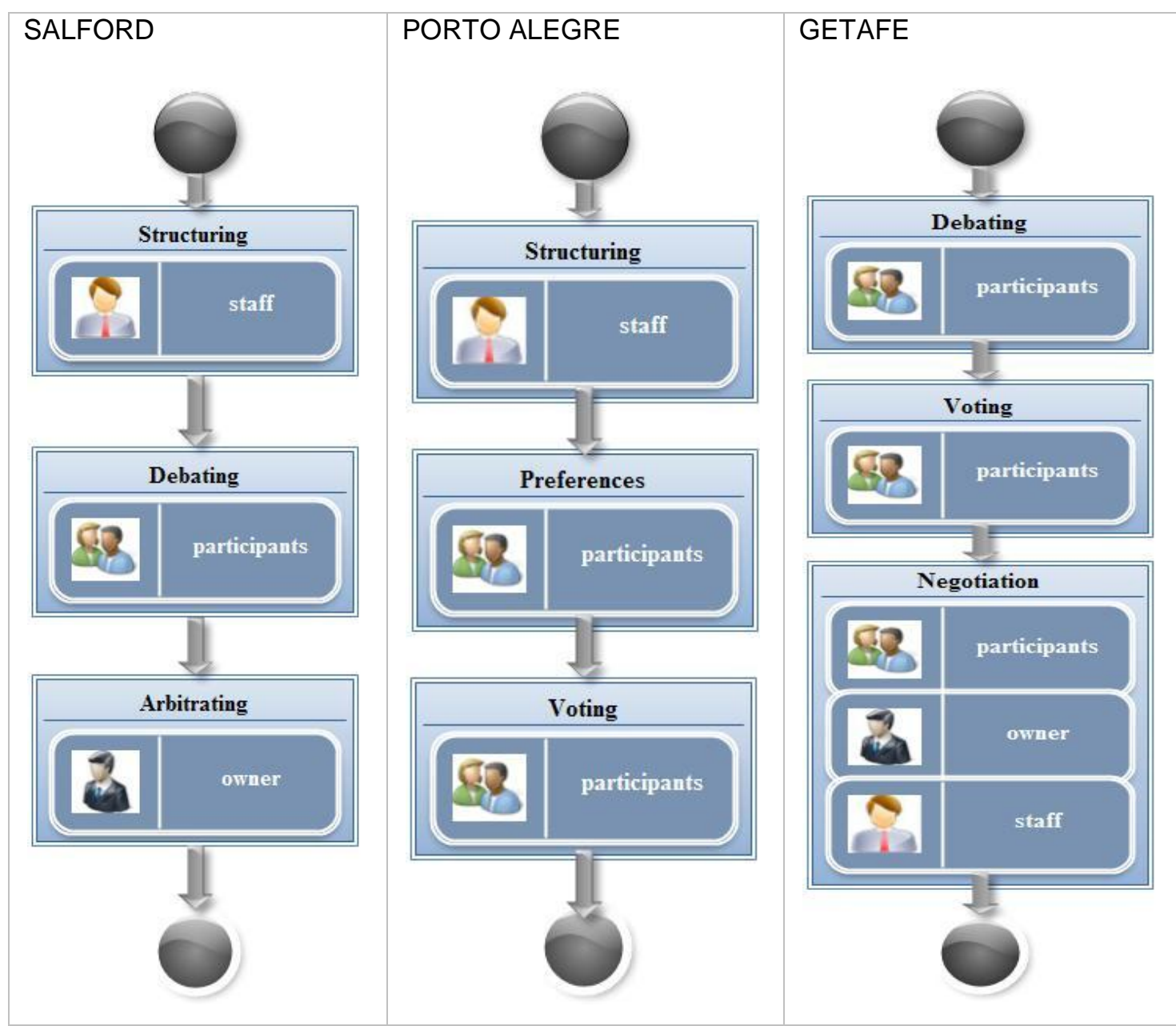

Figure 1: Salford, Porto Alegre and Getafe PB schemes

We should emphasize that, from an ICT point of view, except for a few experiences which use discussion fora to collect electronically suggestions for project proposals as well as votes, there is little use of ICT in PB experiences: they are tipically based on physical meetings, with preferences established through voting, very frequently by showing up hands in public meetings. From the point of view of the little decision technology employed, no formal modelling of citizen preferences is undertaken and no use of negotiation or group decision support tools is used. To sum up, little decision support methodologies are used. That is why we propose, in the next section, a configurable architecture for e-participatory budget formation support.

Note, that we could actually devise a PB comprehensive metastrategy from which we could devise various PBs strategies. Our general strategy could be described as follows: 


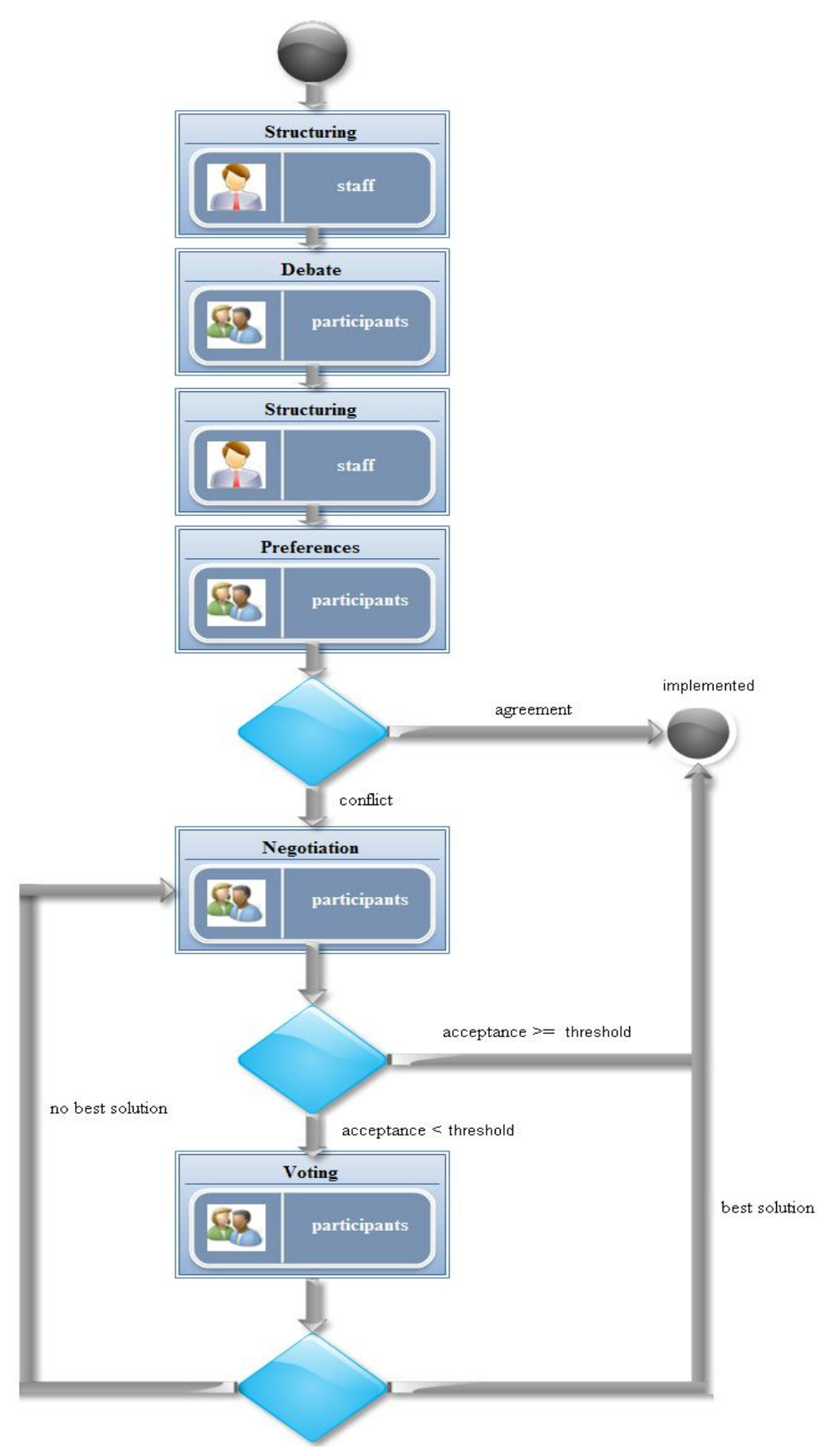

Figure 2: General Scheme of Participatory Budget

\section{A generic architecture}

We describe now a configurable architecture that implements the methodology described before. The goal of our architecture is to provide a technological platform with innovative tools and techniques facilitating electronic participation services, and encouraging the use of ICT, possibly increasing citizen satisfaction, as well as transparency in the budget decision making process.

Our architecture is generic in that it allows deleting or repeating stages to adapt the system to each specific participatory budget process. We describe now our architecture, divided into modules, see Figure 3, which support each of the phases described in Section 2. 


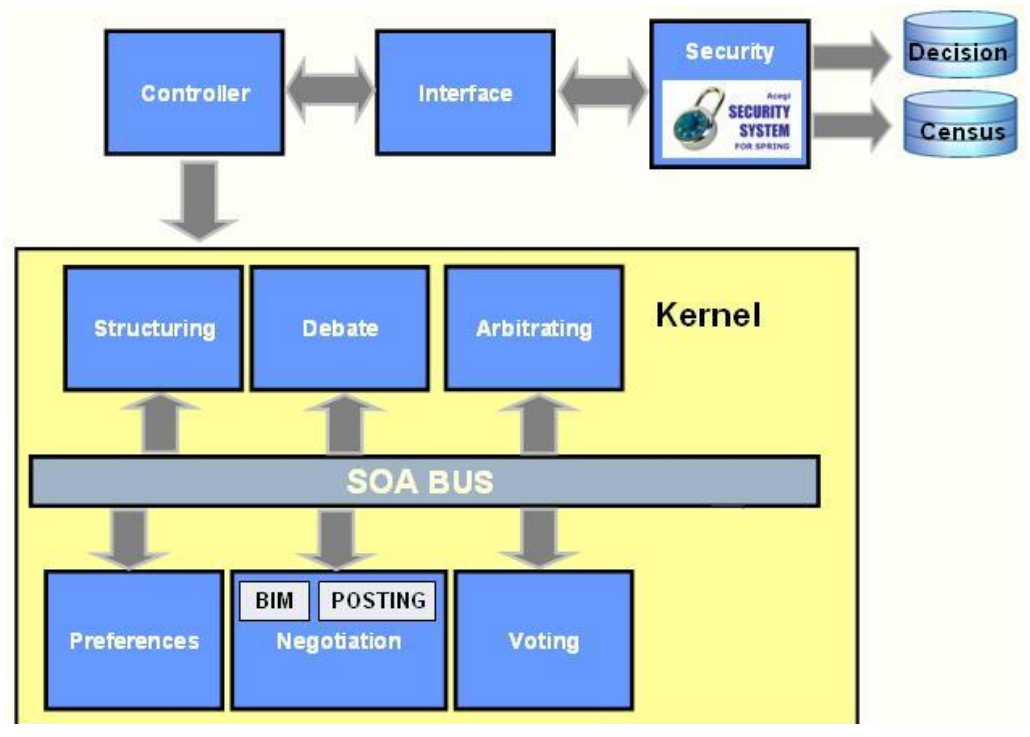

Figure 3: Architecture for participatory budgeting support

The architecture guides the technical staff on behalf of the problem owner and the participants in the participatory budget elaboration process, following a protocol, based on the phases that we have mentioned. At any time, the action that each agent may carry out will depend on his previous action on the system and the actions of agents. As an example, none of the remaining participants may communicate his preferences until the technical staff has finished the budget preparation phase.

The architecture has been implemented with Java/J2EE, Open Source, development technologies (Spring, JSF, Hibernate, Acegi, Maven, Subversion, etc.). From the web technologies point of view, our architecture has been configured as a Service Oriented Architecture (SOA). Thus, it is possible to adopt the Software As a Service (SaaS) philosophy, eliminating the need to install and run the application on the customer's own computer because the application can be hosted as a service provided to customers across the Internet. SaaS can also conceivably reduce the up-front expense of software purchases, through less costly, on-demand pricing. Furthermore, the architecture intends to take a further step in the evolution of Web 2.0, because with it the citizens not only can communicate with others, or express their views, through social networks, blogs, ... but also they will have the opportunity to participate and decide, to enhance transparency in decision making and, possibly, increase their satisfaction.

A relational database management system enables to store and manage information concerning the participatory budget elaboration process. Another database contains the information of all participants, their roles, their permissions, etc... Furthermore, the system has a web based user's interface. To facilitate its use and mitigate the burden of the digital divide, the interface is graphical and simple. It meets all conditions and satisfies the accessibility standards to make Web content accessible to people with disabilities. The controller is responsible for leading the process during all phases. It exchanges information between the different modules of the architecture, and interact with the interface. Thus, the architecture could be offered to various municipalities for their use.

Finally, we include a security module, which is responsible for verifying that users are registered in the application. To login into the system, the users must authenticate themselves using a private password. This module, also, verifies that the user is in the database and has permissions to participate. Then, the system assigns the role that the participant plays and what that user can do within the system, depending on his role. 


\section{Discussion}

The architecture described is a web-services intermediary system aimed at supporting groups in the elaboration of a budget. Rather than using physical meetings with voting mechanisms, we promote meetings through on architecture virtual in which participants can extend the set of alternatives and explore budget consequences. The architecture supports negotiation methods such as POSTING, and the balanced increment method (BIM), but other multilateral negotiation methods could be implemented. If negotiations end up with no agreement, the voting module can be used to decide the budget. The architecture illustrates how we might support groups to make decisions using ICT and decision technologies in the area of participatory budgets. Rather than using new technologies to facilitate standard political decision making mechanisms, such as debating and voting, a more informed and transparent decision, and, even, a more consensual approach is proposed.

\section{References}

Alfaro, C., Gomez,J., Rios, J. (2010). From participatory to e-participatory budgets. In Rios Insua and French (eds), eParticipation: A Group Decision and Negotiation Approach. Springer.

Rios, J., Rios Insua, D. (2008). A methodology for participatory budget formation. Jour. Oper. Res. Soc. 59. 203-212.

Röcke, A. (2008). Participatory budgeting in the UK: from the "grassroots" to the national agenda. The Participatory Budgeting Unit.

Sintomer, Y. (2004). Los presupuestos participativos en Europa: retos y desafíos. IX Congreso CLAD sobre la Reforma del Estado Administración Pública. Madrid.

Sintomer, Y., Herzberg, C., Röcke, A. (2008). Participatory budgeting in Europe: potentials and challenges. Int. Jour. Ur. Reg. Research. 32. 164-178.

Sttefek, J., Kissling, C., Nanz, P. (2008). Civil Society Participation in European and Global Governance: A Cure for the Democratic Deficit?. Basingstoke: Palgrave Macmillan.

\section{About the Author}

\section{Cesar Alfaro}

Cesar Alfaro is Informatics Engineer and a doctoral student at the Department of Statistics and Operative Research (Chair Professor David Rios), Universidad Rey Juan Carlos at Madrid. Professor in Statistics Department of the Universidad Rey Juan Carlos. His doctoral studies focus on E-Democracy. He has working experience as a consultant for information systems. Cesar Alfaro can be contacted at: cesar.alfaro@urjc.es.

Javier Gomez

Javier Gomez is Informatics Engineer and a doctoral student at the Department of Statistics and Operative Research (Chair Professor David Rios), Universidad Rey Juan Carlos at Madrid. Professor in Statistics Department of the Universidad Rey Juan Carlos. His doctoral studies focus on Participatory Budgeting and E-Participation. He has working experience as a consultant for information systems. Javier Gomez can be contacted at: javier.gomez@urjc.es.

Juan J. Molero

Juan J. Molero is degree in Economic Sciences and doctor in Business Administration at the Department of Accounting, Universidad Complutense at Madrid. Professor in Statistics Department of the Universidad Rey Juan Carlos, has been professor in the Universidad San Pablo CEU, Universidad Complutense at Madrid. His investigation focus on financial risk, public accounting, participatory budgeting and environmental risk. Juan J. Molero can be contacted at: juanjose.molero@urjc.es.

Jose M. Lavin

Jose M. Lavin degree in Political Sciences and a doctoral student at the Department of Statistics and Operative Research (Chair Professor David Rios), Universidad Rey Juan Carlos at Madrid. Professor in the Statistics Department of the University Rey Juan Carlos. Professor in the IESCH (Mexico) and associated researcher in European Studies of the UNAM (Mexico). His doctoral studies focus on participatory instruments and E-Democracy. Jose M. Lavin can be contacted at: josemaria.lavin@urjc.es. 